\title{
O DISCIPLINAMENTO DO MERCADO PELO PLANO DIRETOR: O CASO DOS CONDOMÍNIOS DE VERANEIO EM CARAGUATATUBA
}

\section{THE DISCIPLINE OF THE MARKET BY A MASTER PLAN: THE CASE OF BUILDING SUMMER CONDOMINIUMS IN CARAGUATATUBA}

\author{
David Weissberg ${ }^{1}$ \\ Antonio Carlos Machado Guimarães ${ }^{2}$ \\ Pedro Ribeiro Moreira Neto ${ }^{2}$
}

RESUMO: Este artigo apresenta resultados de uma pesquisa que tem como objeto o mercado de segundas residências em Caraguatatuba, no Litoral Norte do Estado de São Paulo. Destaca-se o caso de condomínios de veraneio, de construção mais econômica, dirigidos ao lazer de segmentos de renda intermediária e o impacto das modificações no Plano Diretor daquela cidade na redução de investimentos neste setor.

Palavras-chave: turismo; Plano Diretor.

ABSTRACT: This article presents the results of research on the market for second homes in Caraguatatuba, on the North Shore of São Paulo state. We highlight the case of a condominium resort, which was more economically constructed and addressed to middle-class leisure, and the impact of changes in the urban planning of this city in reducing investments in this sector.

Keywords: tourism; Urban Planning.

\footnotetext{
${ }^{1}$ Mestre em Planejamento Urbano e Regional - UNIVAP. E-mail: d69weissberg@terra.com.br.

2 Docentes do Programa de Pós-graduação em Planejamento Urbano e Regional - UNIVAP. E-mails: guimaraes@univap.br; pedroribeiro@univap.br.
} 


\section{INTRODUÇÃO}

O Litoral Norte do Estado de São Paulo oferece um bom exemplo de um espaço configurado pela atividade turística. Neste plano, a especulação imobiliária é importante vetor, com as construtoras direcionando seus empreendimentos para segmentos específicos do mercado, respeitando seu perfil socioeconômico (GOTTDIENER, 1994).

Contrastando com o glamour das cidades vizinhas, Caraguatatuba se distingue por agregar um turismo dirigido a um público de menor renda como se verifica pelos produtos mais recentemente lançados pelo mercado imobiliário. Isto tem ocorrido particularmente na expansão dos condomínios de veraneio, em processo que teve início ao final dos anos 1980, em que se conjugam a economia no custo da terra, padrões de construção baratos e, naquele momento, uma certa "flexibilização" na aprovação dos projetos (MALTA, 1997).

$\mathrm{Na}$ implantação desses condomínios, concorre ainda a localização privilegiada do município com sua proximidade de importantes centros emissores de turistas (Anexo 1).

Em Caraguatatuba e São Sebastião, onde há uma importante indústria do turismo gerada pelas segundas residências, a expansão urbana é diferenciada das demais cidades da região. Percebemos que os comércios mais comumente usados em Caraguatatuba são os supermercados, lojas de materiais de construção, grandes magazines etc. Cidades como Ubatuba e Ilhabela, por outro lado, mostram um crescimento turístico e urbano voltado ao turismo convencional, em que grande parte dos visitantes elege hotéis e pousadas como meio de hospedagem, utilizam muito mais bares e restaurantes e fazem do comércio de menor porte, como quiosques e lojas de conveniência, sua opção preferencial para as demais compras.

Assim, a expansão de condomínios de veraneio, na região, foi favorecida pelo processo de crescimento da economia, com impacto visível no turismo da classe média, em seus extratos de menor renda. Dessa forma, segmentos da população, antes com participação reduzida nas atividades turísticas, veem crescer a oportunidade de possuir ou ao menos alugar uma casa de praia.

$\mathrm{Na}$ pesquisa desenvolvida, observouse que os condomínios de veraneio são uma tendência de edificação cada vez mais utilizada na cidade de Caraguatatuba. Na maioria dos casos, são unidades geminadas num prédio horizontal, que conduz a um maior aproveitamento do espaço e à redução de custos do processo construtivo dessas edificações, influindo, decisivamente, no número crescente desses empreendimentos. Tais estudos buscaram a quantificação das unidades habitacionais dos condomínios em relação à sua metragem quadrada, ao número de cômodos e à sua disposição em cada unidade residencial.

Coloca-se, então, em questão as possíveis consequências desse processo na ocupação do espaço urbano e o papel que o planejamento e legislação podem ocupar em seu disciplinamento.

Em Caraguatatuba, a expressão desse processo se traduz pela expansão urbana nos bairros periféricos de potencial turístico. 
Essa formação gerou um tipo de segregação socioespacial, na qual a própria população original da cidade, por fatores diversos, mas, principalmente, de ordem econômica, foi deslocada para áreas distantes da orla marítima, cedendo espaço para um novo modelo de ocupação espacial, promovido pela especulação imobiliária e marcado por "ilhas de prosperidades" nas regiões mais nobres e zonas turísticas da cidade, desta vez reservadas para um novo tipo de "morador", transitório.

Recentemente, foram observadas mudanças no ordenamento espacial daquela cidade, particularmente após o Plano Diretor de 2007, já observando uma desaceleração no número de lançamentos de condomínios de veraneio.

Nesse sentido, definiu-se como objetivo deste trabalho o estudo do turismo residencial e, o especifico, a classificação e a análise dos condomínios de veraneio como componente de transformação espacial; destacando o caso das segundas residências no formato dos condomínios de veraneio (BOULLON, 2002), considerando que esse tipo de edificação tende a crescer de forma generalizada e acentuada por todo - Litoral Norte, em especial na cidade de Caraguatatuba.

\section{METODOLOGIA}

Tendo em vista os objetivos, foram coletados dados no Cartório de Registro de Imóveis e empresas do ramo imobiliário, nos bairros onde se verificavam lançamentos desse tipo de condomínio, buscando levantar a área útil dos imóveis, a taxa de ocupação do terreno e seu preço.
Posteriormente, tais dados foram confrontados com as leis municipais, destacando o Plano Diretor e a Lei de Zoneamento.

\section{DESENVOLVIMENTO}

Tulik (1995) comenta que "A expressão maior do turismo de fim de semana (embora também possa ser utilizada nas férias), a residência secundária, tem sua localização definida pela relação tempo-custo-distância." A distância reduzida ou a excelência das condições de acesso podem favorecer a presença de residências secundárias como acontece com alguns itinerários privilegiados que concentram a maioria dos fluxos.

O Litoral Norte de São Paulo concentra cerca de $25,4 \%$ do fluxo turístico no Estado. A Tabela 1 mostra a variação de fluxos no período de 1999 e 2002 e, segundo os dados coletados, o maior fluxo percentual de turistas é da cidade de São Paulo e de cidades do Vale do Paraíba, justificado pela citada relação da proximidade e o curto tempo de deslocamento que se traduz, em ambos os casos, em economia.

Para identificar a origem dos turistas, a Secretaria de Turismo, junto com a Associação Comercial de Caraguatatuba, realizou uma pesquisa na qual constatou os principais polos emissores de demanda no Estado de São Paulo. 


\section{Tabela 1 - Principais cidades emissoras de turistas para Caraguatatuba}

\begin{tabular}{lcc}
\hline \multicolumn{1}{c}{ CIDADE } & $\mathbf{1 9 9 9}$ & $\mathbf{2 0 0 2}$ \\
\hline Guaratinguetá & $1,80 \%$ & $1,60 \%$ \\
Campinas & $3,30 \%$ & $2,0 \%$ \\
Caçapava & $1,50 \%$ & $3,0 \%$ \\
Jacareí & $5,50 \%$ & $4,60 \%$ \\
Guarulhos & $4,90 \%$ & $5,30 \%$ \\
São José dos Campos & $16,80 \%$ & $16,60 \%$ \\
São Paulo & $29,60 \%$ & $35,20 \%$ \\
Outros & $36,60 \%$ & $31,70 \%$ \\
\hline
\end{tabular}

Fonte: Associação Comercial de Caraguatatuba Pesquisa, divulgada em 2003.

Em Caraguatatuba, a lei de zoneamento especifica como zonas turísticas aquelas em que se situam os loteamentos destinados à população flutuante ${ }^{1}$ : Tabatinga, Mococa, Massaguaçu, Martim de Sá, Prainha, Indaiá, Pan-Brasil, Praia das Palmeiras e parte da Fazenda Serramar. Já os condomínios de veraneio são definidos pela lei do Plano Diretor, em seu capítulo III, "Do uso e ocupação do solo", como categorias de uso residencial multifamiliar, destinadas, exclusivamente, à residência multifamiliar horizontal ou vertical, correspondendo a mais de uma habitação por lote.

\footnotetext{
1 Sobre loteamentos destinados à população flutuante ver BOULLON, 2002.
}

Tais edificações permitem uma redução de custos por dois fatores; primeiramente, pelo aproveitamento no parcelamento do solo onde um único lote podia, de acordo com a legislação anterior, aceitar até seis residências; e, em segundo, pela redução nos gastos decorrentes da construção padronizada.

Os gráficos, a seguir, indicaram 0 crescimento quantitativo dos condomínios de veraneio e a sua distribuição espacial. A pesquisa indica o crescimento dos bairros aliado à proliferação dos condomínios de veraneio, agregando, ainda, dados relativos ao número de dormitórios, metragem das residências como indicadores de condições socioeconômicas dos turistas de segunda residência. 
Gráfico 1 - Número de empreendimentos por ano

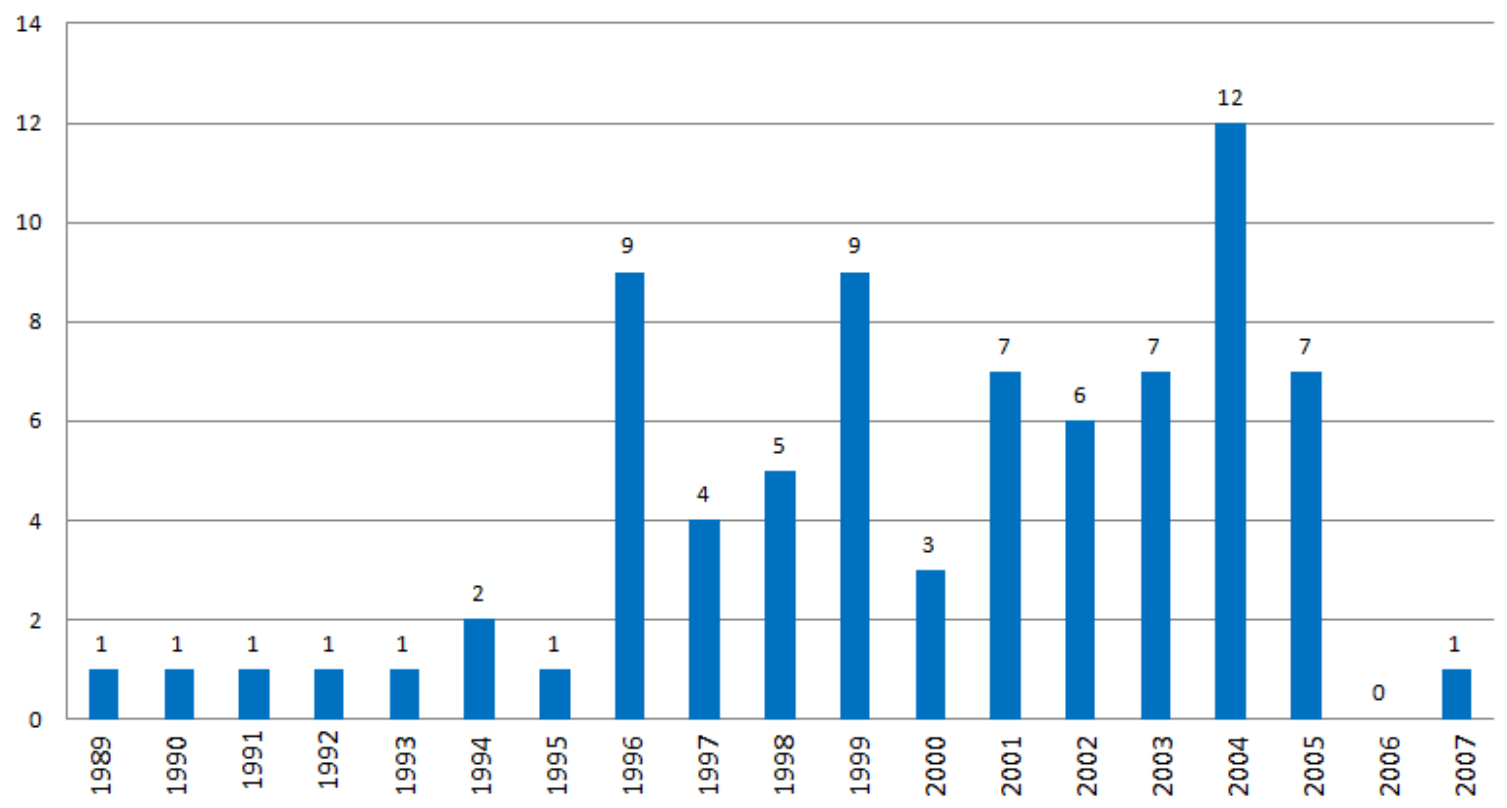

Os dados do Gráfico 1 mostram o crescimento dos condomínios ocorrido, principalmente, entre os anos de 1998 a 2007. Nesse período, as incorporadoras e construtoras investiram principalmente na construção de condomínios horizontais, aproveitando 0 baixo custo desses empreendimentos e as vantagens possibilitadas pela antiga lei do parcelamento do solo que permitia um coeficiente de aproveitamento de até $70 \%$.

Apesar de terem sido encontrados alguns empreendimentos entre os anos 1989 e 1996, observa-se sua aceleração no período subsequente (1998-2007). Acreditase que essa tendência acompanhou um momento de crescimento da economia brasileira, uma vez que foi observado, no mesmo período, um crescimento anual de
9\%, em média, no número de turistas. Essa observação, em certa medida, aponta a hipótese de que a emergência desse tipo de segunda residência se liga à incorporação de novos segmentos socioeconômicos à atividade turística. Afinal, esse tipo de imóvel oferece uma opção turística relativamente barata, se comparada com os valores despendidos em hotéis e restaurantes, justificada pelo custo baixo de hospedagem, ou seja, a economia nos valores da compra, do aluguel, ou, ainda, a economia nos custos de alimentação e lazer. Sua localização, contudo, manteve-se restrita a algumas áreas da cidade. Em grande parte, tal localização seguiu uma lógica de mercado, dificultando um maior esforço no ordenamento territorial. Vejamos como os condomínios se distribuem. 


\section{Gráfico 2 - Evolução e Localização dos Empreendimentos em Caraguatatuba}

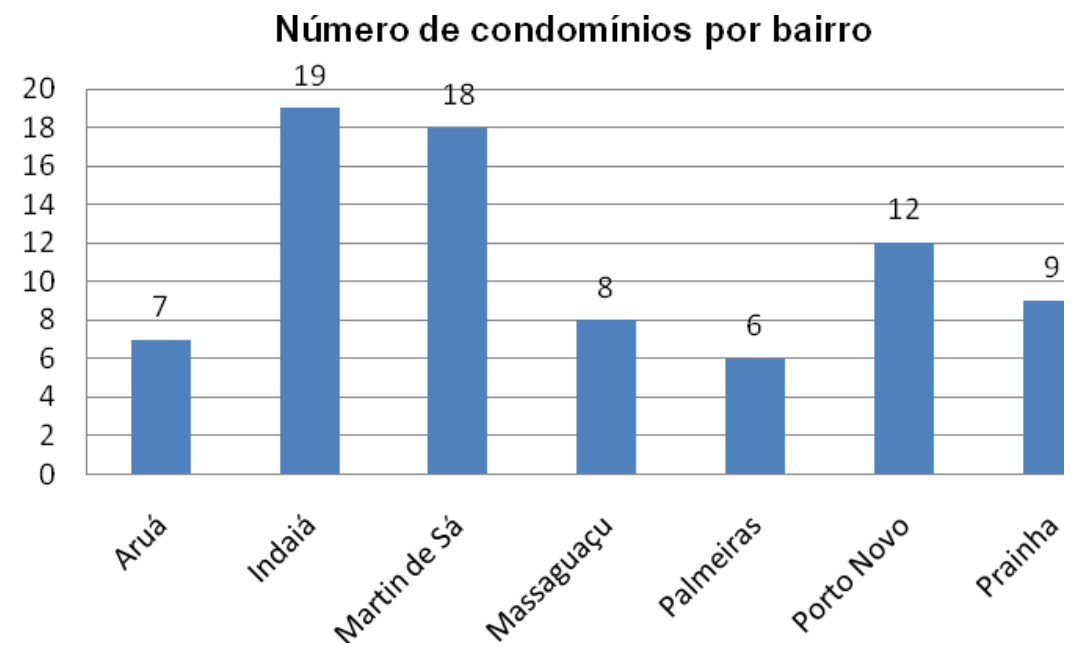

Total de unidades residenciais: 714

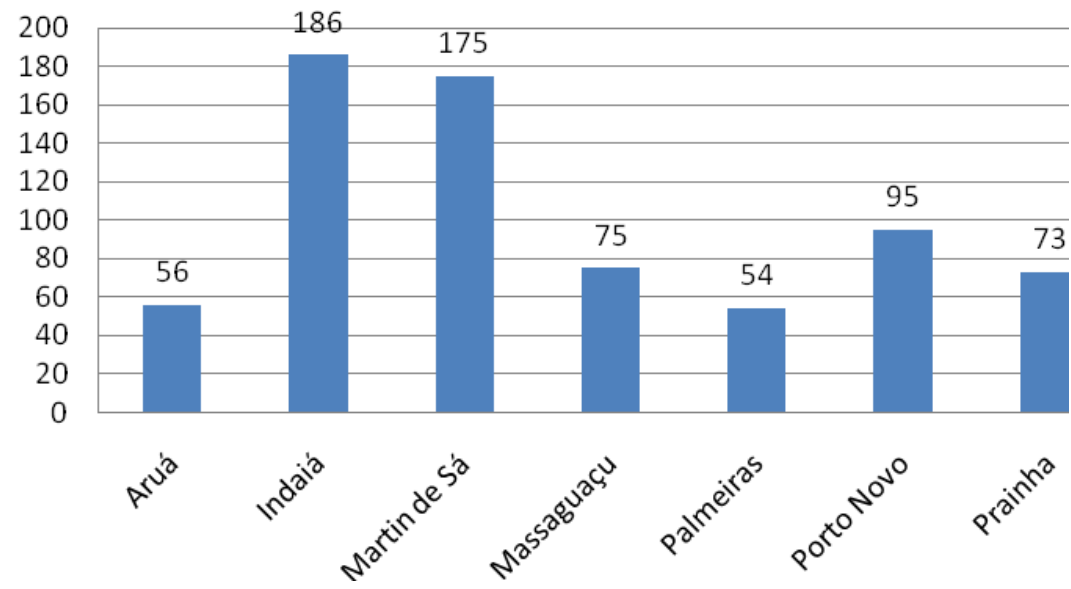

Nota-se que os bairros do Indaiá e Martin de Sá tiveram maiores investimentos em comparação aos demais. Vale ressaltar que esses dois bairros estão em lados opostos da cidade, em relação ao centro. Outro dado importante refere-se aos bairros de Aruá e Palmeiras, ambos com o menor número de investimentos. Considerando o fato desses dois bairros possuírem melhor infraestrutura e maior desenvolvimento urbano, fica a sugestão de sua reserva para fins de especulação imobiliária.

Os lançamentos imobiliários observados na praia de Martin de Sá são bons exemplos desse tipo de imóvel. Em visitas ao local, foi possível notar que cada unidade pode abrigar até 8 pessoas entre os quartos e a sala (a maioria com sofá-cama e beliches) e, no cruzamento desses dados, teremos um total de 1400 turistas de segunda residência nesse bairro considerado como uma área urbana consolidada com média taxa de ocupação.

Os valores praticados por unidade são, em média, $\mathrm{R} \$ 67.500,00$, na Praia das Palmeiras, ou seja, cerca de $R \$ 940,11 / \mathrm{m}^{2}$. 
Esses valores podem ser justificados, talvez, por dois motivos. Primeiramente, a falta de infraestrutura básica (pavimentação, saneamento de água, iluminação pública e comunicação). Durante a visita ao local, pôde ser observada a total falta de infraestrutura e, por um segundo motivo, pela balneabilidade da praia, bastante precária, conforme dados da CETESB que qualificam a água constantemente inapropriada para o banho.

$\mathrm{Na}$ legislação anterior, havia certo favorecimento à implantação desse tipo de empreendimento. Conforme mencionado, a possibilidade de se ocupar o terreno, em até $70 \%$, influenciava, significativamente, na redução dos custos. No ano de 2007, contudo, uma nova lei de zoneamento veio modificar essa situação. Com a nova taxa de ocupação do terreno fixada em $50 \%$, por meio do artigo 141, foi adicionado um acréscimo aos valores iniciais. Em efeitos práticos, um lote com $600 \mathrm{~m}^{2}$, em que seria possível construir até sete unidades nesse padrão, passaria a comportar, no máximo, cinco unidades. Daí a queda no número de lançamentos observada no Gráfico 1.

\section{CONSIDERAÇÕES FINAIS}

O mercado imobiliário define e direciona seus investimentos conforme a disponibilidade de terras e as facilidades ou dificuldades - impostas pelo Estado, por intermédio das leis de zoneamento. Em
Caraguatatuba, essas leis atuaram, a princípio, como um facilitador para implantação de projetos de baixo custo, dirigidos a segmentos de menor renda.

Modificações introduzidas no texto legal, com a aprovação de um novo Plano Diretor, em 2007, apontam para o desaquecimento desse nicho de mercado. Fica em aberto a questão de desdobramentos futuros desse quadro, com as incorporadoras disputando, voltados a antigos parâmetros ou, no sentido oposto, buscando novos segmentos de mercado. Em qualquer alternativa, permanece a questão do impacto da atividade turística no ordenamento espacial.

\section{REFERÊNCIAS}

BOULLON, R. Planejamento do Espaço Turístico. São Paulo: EDUSC, 2002.

GOTTDIENER, M. A Produção Social do Espaço Urbano. São Paulo: EDUSP, 1994.

MALTA, F. J. N. C. Planejamento e gestão do turismo no litoral norte paulista. In: YÁZIGI, E.; ALESSANDRI, A. F.; CARLIOS, R. C. A. C. (Org.). Turismo, Espaço, Paisagem e Cultura. São Paulo: Hucitec, 1997.

TULIK, O. Residências Secundárias: as fontes estatísticas e a questão conceitual. Revista Turismo em Análise, São Paulo, v. 6, n. 2, p. 26-34, nov. 1995 


\section{ANEXO 1}

Distâncias Rodoviárias do Centro de Caraguatatuba

\begin{tabular}{lcccccc}
\hline \multicolumn{1}{c}{ Cidade } & São Paulo & Campinas & S. J. Campos & Santos & Guarujá & Caraguatatuba \\
\hline São Paulo & $-0-$ & $97 \mathrm{Km}$ & $99 \mathrm{Km}$ & $79 \mathrm{Km}$ & $97 \mathrm{Km}$ & $174 \mathrm{Km}$ \\
Campinas & $97 \mathrm{Km}$ & $-0-$ & $153 \mathrm{~km}$ & $174 \mathrm{Km}$ & $193 \mathrm{Km}$ & $234 \mathrm{Km}$ \\
S. J. Campos & $99 \mathrm{Km}$ & $153 \mathrm{~km}$ & $-0-$ & $166 \mathrm{Km}$ & $155 \mathrm{Km}$ & $89 \mathrm{Km}$ \\
Santos & $79 \mathrm{Km}$ & $174 \mathrm{Km}$ & $166 \mathrm{Km}$ & $-0-$ & $11 \mathrm{Km}$ & $165 \mathrm{Km}$ \\
Guarujá & $97 \mathrm{~km}$ & $193 \mathrm{Km}$ & $155 \mathrm{Km}$ & $11 \mathrm{Km}$ & $-0-$ & $156 \mathrm{Km}$ \\
Caraguatatuba & $174 \mathrm{Km}$ & $234 \mathrm{Km}$ & $89 \mathrm{Km}$ & $165 \mathrm{Km}$ & $156 \mathrm{Km}$ & $-0-$ \\
\hline
\end{tabular}

Fonte: Guia 4 Rodas. 